\title{
Intercomparison Exercise at Harshaw 6600, DVG-02TM, and D-Shuttle Dosimeters for the Individual Monitoring of Ionizing Radiation
}

\author{
Dmitriy Spartakovich Kim ${ }^{1, *}$, Kentaro Murayama ${ }^{2}$, Yernat Nurtazin ${ }^{1}$, Yasuhiro Koguchi ${ }^{2}$, Yergazy Kenzhin ${ }^{1}$, \\ Hiroshi Kawamura² \\ ${ }^{1}$ Institute of Nuclear Physics, Kazakhstan; ${ }^{2}$ Chiyoda Technol Corporation, Japan
}

\section{Technical Paper}

Received October 16, 2018

Revision January 21, 2019

Accepted May 20, 2019

Corresponding author: Dmitriy Spartakovich Kim

Institute of Nuclear Physics, 1 lbragimov str., city of Almaty 050032, Kazakhstan

Tel: +7-700-095-19-45

Fax: +7-727-386-52-60

E-mail:dmitriy.kim@ukr.net, kim2@inp.kz

This is an Open-Access article distributed under the terms of the Creative Commons Attribution NonCommercial License (http://creativecommons.org/ licenses/by-nc/4.0) which permits unrestricted noncommercial use, distribution, and reproduction in any medium, provided the original work is properly cited.

Copyright $\odot$ 2019The Korean Association for Radiation Protection

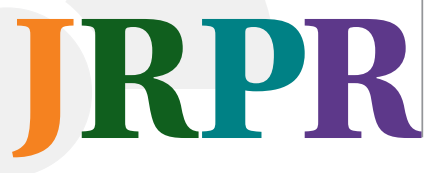

Background: The main goal of experiments is to compare various operational and technical characteristics of D-Shuttle semiconductor personal dosimeters of the Japanese company "Chiyoda Technol Corporation" and Harshaw thermoluminescent dosimeters (TLD) manufactured by "Thermo Fisher Scientific" and DTL-02 of the Russian Research and Production Enterprise (RPE) "Doza" by their occupational and calibration exposure at various dose equivalents from 0.5 to $20 \mathrm{mSv}$ of gamma-radiation.

Materials and Methods: Besides dosimeters DTL-02, D-Shuttle and Harshaw TLD, there were also used: (1) the primary reference radionuclide source Hopewell Designs IAEA: G10-112 with ${ }^{137} \mathrm{Cs}$ isotope (an error is not more than $6 \%$ and activity is $20 \mathrm{Ci}$ ), and (2) the verification device UPGD-2M of RPE "Doza" and installed in the National Center for Expertise and Certification of the Republic of Kazakhstan (Kapchagai, the National Center for Expertise and Certification).

Results and Discussion: The main results of researches are the following: (1) TLDs for Harshaw 6600 and DVG-02TM have an approximately equal measurement accuracy of the individual dose equivalents in the range from 0.5 to $20 \mathrm{mSv}$ of gamma-radiation. (2) Advantages of dosimeters for Harshaw 6600 are due to the high measurement productivity and opportunity to indicate the dose on the skin $\mathrm{H}_{\mathrm{p}}(0.07)$. Advantages of DVG-02TM consist of operation simplicity and lower cost than of Harshaw 6600. (3) D-Shuttles are convenient for use in the current and the operational monitoring of ionizing radiation. Measurement accuracy and $10 \%$ linearity of measurements are ensured when D-Shuttle is irradiated with dose equivalents below $1 \mathrm{mSv}$ at the equivalent dose rate not higher than $3 \mathrm{mSv} \cdot \mathrm{hr}^{-1}$. This allows using D-Shuttle at a routine technological activity.

Conclusion: The obtained results of experiments demonstrate advantages and disadvantages of D-Shuttle semiconductor dosimeters in comparison with two TLD systems of DVG-02TM and Harshaw 6600.

Keywords: Ionizing radiation, External irradiation, Dosimetry, Personal monitoring, Radiation protection, Thermoluminescent dosimeter, Semiconductor dosimeter, D-Shuttle, Harshaw 6600, DVG-02TM

\section{Introduction}

Individual dosimetry is an important component of radiation safety that ensures compliance with the established radiation dose limits, controlled by means of measur- 
ing instruments. To date, thermoluminescent method of individual dosimetry is widely used. Among the existing thermoluminescent systems for individual dosimetry control (IDC), conducted with a certain periodicity at normal operation with sources of ionizing radiation (IRS), the Russian DVG-02TM of RPE "Doza" (Moscow, Russia) and the American Harshaw 6600 are in use in Kazakhstan. A number of features that determine its efficiency characterize every system. In 2011, the Japanese company "Chiyoda Technol Corporation" together with the National Institute of Advanced Industrial Science and Technology (AIST) developed semiconductor dosimeters D-Shuttle, originally intended for carrying out the IDC for the citizen especially children and pregnant women in Fukushima Prefecture after the accident at the nuclear power plant. All three IDC systems have different costs and can be compared mainly according to the principle of operation and range and accuracy of measurements.

Radiation safety is the state of protection of the present and future generations of people from the harmful effects of ionizing radiation. The main task of radiation protection is prevention of human exposure to radiation doses exceeding permissible limits [1]. The general controlled parameters of radiation safety are the dose limits of individual exposure, since the basis for their reduction is the measurement of physical factors.

\section{Materials and Methods}

Individual monitoring of the external ionizing exposure is a mandatory requirement for all organizations working with sources of ionizing radiation. It consists of measuring personal dose equivalents $\mathrm{H}_{\mathrm{p}}(0.07), \mathrm{H}_{\mathrm{p}}(3)$ and $\mathrm{H}_{\mathrm{p}}(10)$ related to equivalent dose of the skin, lens of the eye and effective dose, respectively. The probability of long-term adverse exposure effects of ionizing radiation on a person from the dose evenly accumulated for a long time is evidently lower than for a single irradiation with the same dose. In the normal operation of radioactive sources, when the daily individual dose of occupational exposure is predictable and relatively constant, one carries out the current individual dosimetry control (IDC). In addition to the current IDC, there are also the operational and emergency kinds of IDC. The operational IDC is usually carried out by means of the real time direct-reading dosimeters with option of setting the maximum threshold, which exceeding triggers the activation of sound and/or light alarms that provides steady occupational gamma-irradiation with an annual effective dose of no more than $20 \mathrm{mSv}$, and emergency IDC is necessary in case of increased exposure, in the event of a radiation accident [2]. However, current IDC is still the main type of IDC, and it is carried out by using the various dosimeters: thermoluminescent, semiconductor, photographic, and gas-discharged.

Solid-state detectors are much more convenient than gas discharged and photographic ones, since they provide better reliability of storing the dose information and smaller measuring error as well. Among the solid-state detectors, thermoluminescent materials consisting of aluminum oxide or lithium fluoride and transforming the absorbed energy of ionizing radiation into luminescence under the action of thermal excitation (heating) at a temperature of $+300-400^{\circ} \mathrm{C}$, as well as semiconductors of silicon or germanium crystals, were most widely used.

\section{Russian TLD system/badge design and operation and physics behind that}

To date, the DVG-02TM (Figure 1), developed by the Federal State Unitary Enterprise "Scientific Research Institute of Industrial and Marine Medicine" of the Federal Medical and Biological Agency of Russia, which have been substantially modernized by RPE "Doza" and currently produced under the name of Doza-TLD, and Harshaw 6600 (Figure 2) of the world-famous manufacturer of innovative equipment Thermo Fisher Scientific, are the most common systems used for conducting current IDC. Indications of thermoluminescent dosimeters are read out in both devices. In Harshaw 6600 readings are processed by means of WinREMS software and

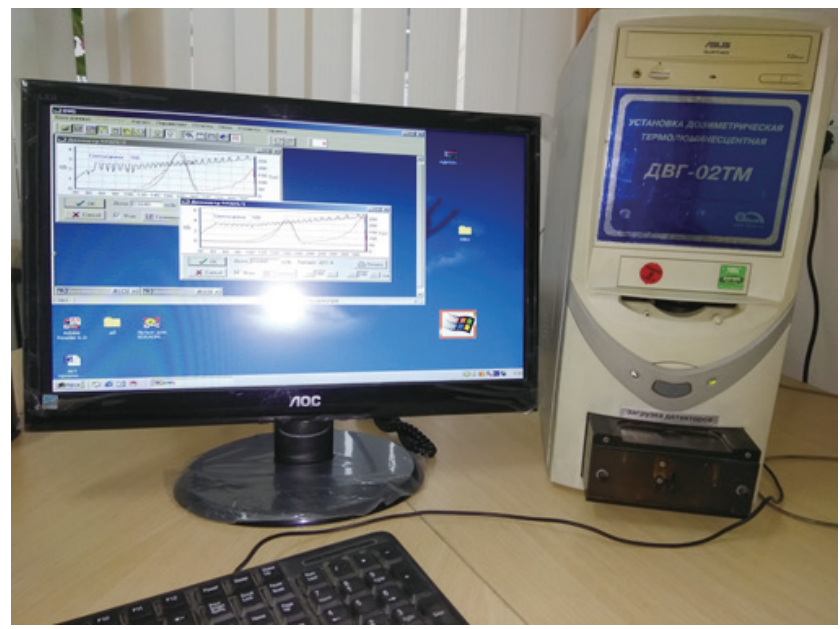

Fig. 1. DVG-02TM, the system for the individual monitoring of ionizing radiation. 


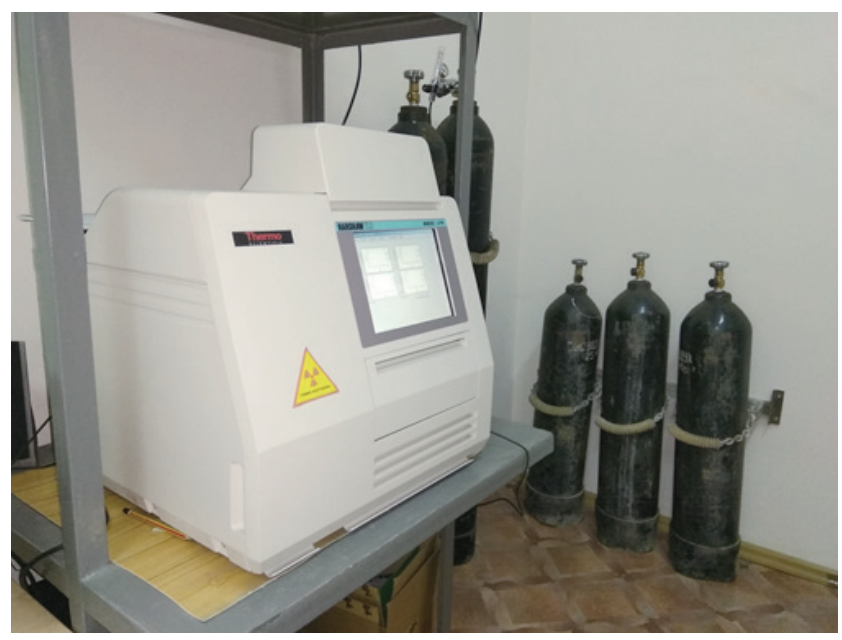

Fig. 2. Harshaw 6600, the system for the individual monitoring of ionizing radiation.

mathematical algorithms WinAlgorithms, set up for dosimeters with two or four crystal detectors respectively, in order to subsequently determine the operational values in the fields of mixed ionizing radiation. In the system of DVG-02TM, the dose equivalent values in the field of ionizing radiation of a certain type are measured with thermoluminescent dosimeters with detectors of tissue-equivalent material of density $1 \mathrm{~g} \cdot \mathrm{cm}^{-3}[3]$, then the results of registration of radiation doses are processed using DVG software.

The system of DVG-02TM is to measure the personal dose equivalent of $\mathrm{H}_{\mathrm{p}}(10)$ from $50 \mu \mathrm{Sv}$ to $10 \mathrm{~Sv}$ in the photon energy range of $0.015-3 \mathrm{MeV}$, as well as the dose equivalents $\mathrm{H}_{\mathrm{p}}(0.07)$, $\mathrm{H}_{\mathrm{p}}(3)$ and $\mathrm{H}_{\mathrm{p}}(10)$ related to equivalent dose of the skin, lens of the eye and effective dose, respectively from $2 \mathrm{mSv}$ to $10 \mathrm{~Sv}$ in the energy range of $0.015-1.25 \mathrm{MeV}$ of photon radiation and $0.25-3.5 \mathrm{MeV}$ of beta-radiation. DVG-02TM was equipped with thermoluminescent dosimeters DTL-02 with LiF detectors for measuring the dose from $1 \mathrm{mGy}$ to $10 \mathrm{~Gy}$ with loss of information up to $5 \%$ per year and stiffness stroke of about $30 \%$ in the range from $60 \mathrm{keV}$ to $1.25 \mathrm{MeV}$ [4]. Despite the decrease in the sensitivity of TLDs because of grain consolidation in the structure of the detecting substance after annealing, the dosimeters DTL-02 meet the requirements for homogeneity and reproducibility of indications for multiple irradiations.

$\mathrm{LiF}$ thermoluminescers heating to a temperature of about $+400^{\circ} \mathrm{C}$ provides reading out indications of DTL-02 dosimeters (Figure 3). In the result, free electrons and holes arising under the effect of ionizing radiation, receive the additional free energy and recombine with each other. The thermal

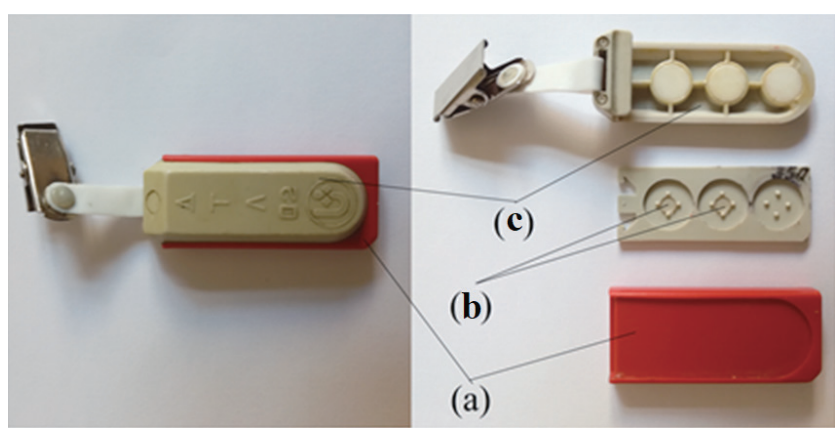

Fig. 3. The design of the individual dosimeter DTL-02 of the system DVG-02TM (a) the dosimeter body, (b) crystal detectors, (c) cover filter.

emission or emission of a light flux accompanies this process. The change of thermoluminescence flux intensity indicates the dose absorbed by the detectors. The glow curves, which characterizes the dependence of its intensity on the heating temperature of LiF detector, has several peaks. The software of DVG-02TM automatically calculates the area under the maximal peak. Using the integral method of reading thermoluminophore information minimizes the error of calculations.

The operation of DTL-02 dosimeters includes their exposure in the field of ionizing radiation and its energy accumulation in thermoluminophores. This energy converts to a numerical value proportional to the dose as the result of alternate linear or step heating of detectors in the reader of DVG$02 \mathrm{TM}$ unit. The stepwise change in the temperature of the heater ensures the relative speed of the reader due to the maximum rate of reaching the preheating and annealing temperatures and its support during the heating period at $2^{\circ} \mathrm{C} \cdot \mathrm{s}^{-1}$ and above. The reader of the unit heats crystal detectors alternately. Heating of each subsequent thermoluminophore begins as soon as the temperature background formed because of the previous heating reduces to $69^{\circ} \mathrm{C}$. Software converts the obtained values of the thermally stimulated luminescence into a histogram of distribution, which is processed by an integral or peak method.

Measuring the readings by annealing the crystal detectors irradiated with different dose equivalents also allows calibrating the reader of the DVG-02TM unit. Usually several batches of several control dosimeters are irradiated for calibration. Detectors of dosimeters irradiated with identical doses are sequentially placed in the reader, and both the personal dose equivalent and the sensitivity of the detecting material (impulse per mSv) are calculated from the results of 
measurements. It has become possible to change manually the sensitivity of detectors of DTL-02 dosimeters during the process of calibration of the reader DVG-02TM, despite the fact that the equipment manufacturer does not provide this opportunity.

\section{USA TLD system/badge design and operation and physics behind that}

Harshaw 6600 unit is designed to measure the personal dose equivalent in terms of the effective dose in the whole the body $\mathrm{H}_{\mathrm{p}}(10)$, on the skin $\mathrm{H}_{\mathrm{p}}(0.07)$ and in the eye lens $\mathrm{H}_{\mathrm{p}}(3)^{1)}$ from $0.1 \mathrm{mSv}$ to $10 \mathrm{~Sv}$ in the energy range $0.03-6 \mathrm{MeV}$ of photon radiation, $25 \cdot 10^{-6}-10 \mathrm{MeV}$ of neutron and more than $0.07 \mathrm{MeV}$ of beta-radiation [6]. The operation of Harshaw 6600 is technically more complicated than of DVG02TM.

Before operating the Harshaw 6600 dosimetry system, both the reader and dosimeters (Figure 4), including 2-4 crystal detectors of $\mathrm{LiF}, \mathrm{CaF}_{2}$ or $\mathrm{Al}_{2} \mathrm{O}_{3}$, must be calibrated.

The operator of the Harshaw 6600 system first irradiates all the present dosimeters with embedded strontium-yttrium radionuclide source ${ }^{2)}$ of activity of $18.5 \mathrm{MBq}$ that provides sequential irradiation and reading of each chipstrate and recommended for use. The energy of ${ }^{90} \mathrm{Sr}+{ }^{90} \mathrm{Y}$ is related with thermoluminophors sensitivity in the equivalent dose calcu-
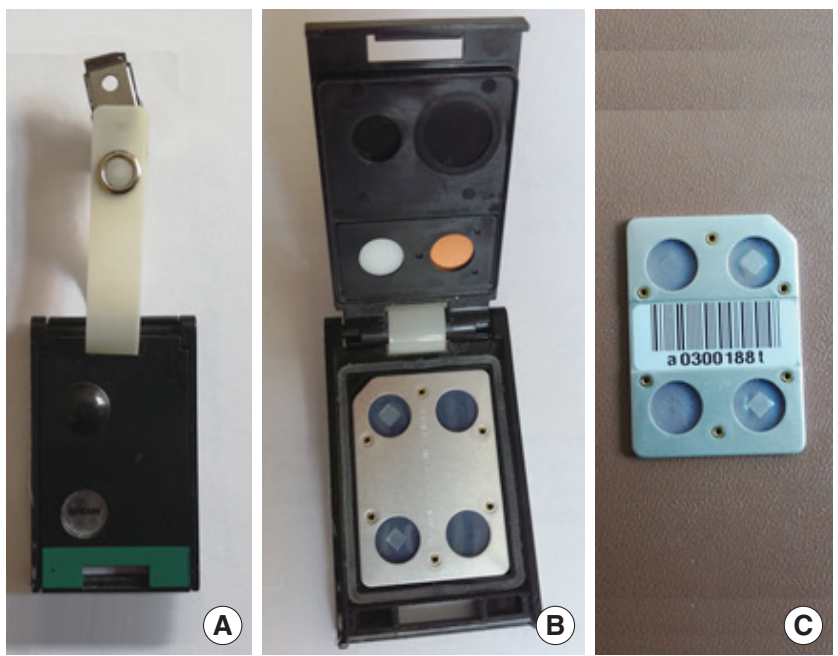

Fig. 4. Design of the individual thermoluminescent dosimeter Harshaw 6600. (A) Dosimeter with closed lid-filter, (B) dosimeter with an open lid-filter, (C) chipstrate with crystal detectors. lation algorithms of WinREMS and WinAlgorithms. However, the practical experience of operating the Harshaw 6600 indicates that when performing calibration in the absence of ${ }^{9}{ }^{90} \mathrm{Sr}+{ }^{90} \mathrm{Y}$ radionuclide source, it is also possible to use IRS with ${ }^{137} \mathrm{Cs}$ isotope of the same activity - the difference in the dosimeter readings does not exceed $5 \%$.

The result of dosimeters' calibration is the choice of the most sensitive dosimeters (with an error of no more than $5 \%)$, called calibration or "golden" dosimeters. The number of "golden" dosimeters should be $1-2 \%$ of the total quantity of dosimeters of a certain type. At the same time, working dosimeters of DVG-02TM system can be used for calibration, but the "golden" dosimeters of Harshaw 6600 should not be used for the IDC. Besides the calibration dosimeters, the ones for the control of data and background quality are also free of direct application for the dosimetry monitoring purpose. These dosimeters are often selected out of those that either had been rejected or not recognized by the reader and were not included in its information base.

Calibration of the Harshaw 6600 reader is performed by irradiating the "golden" dosimeters with a certain dose (usually $5 \mathrm{mSv}$ ) and reading their indications to determine the reader calibration factor (RCF) for each thermoluminescent element that converts the conventional units of measurement (Cl) into the dose equivalent (Sv).

In the result of calibration of dosimeters and the reader of Harshaw 6600 one should determine the following parameters for every type of dosimeters: sensitivity of detection material, working area, temperature profile, parameters of data collection modes for annealing, as well as the calibration of dosimeters and reader both in the conventional units $(\mathrm{Cl}$ and gU) and in sieverts (Sv). Because of DVG-02TM calibration, one can determine only sensitivity of the detection material correlated with a certain radiation dose.

After detecting the "golden" dosimeters, the remaining ones are irradiated with a certain dose equivalent, their indications are read out. The working or "field" dosemeters are calibrated and registered in the information base of the reader with assignment of correction factors (ECC) according to the accuracy of dosimeter indications. The rejected dosimeters can be repeatedly irradiated and measured unlimited number of times until they are recognized by the

1) To measure the individual dose equivalent in the eye lens $\mathrm{H}_{\mathrm{p}}(3)$, a special and rather expensive calculation algorithm is required.

2) The reader of Harshaw 6600 , besides the built-in strontium-yttrium irradiator, also includes a closed IRS with a radioisotope of ${ }^{14} \mathrm{C}-\mathrm{a}$ reference light source used to stabilize the operation of the photoelectric multiplier (PMT). The automatic control of stability of the system measuring path and the reader parameters quality be gins after the turning on and is performed at the beginning and at the end of the measurements and every 10 readings of indications of the "field" dosimeters after recognition (with ECC correction factors determination) and annealing. 
reader and referred to the number of "field" ones.

At the beginning of the measurements, Harshaw 6600 reads the heating, and at the end, the controlled cooling of the TL elements occurs. Unlike DVG-02TM, the cooling is due to the use of high-purity dry nitrogen (99.995\%), which penetrates into the reader under pressure $3-7 \mathrm{kgf} \cdot \mathrm{cm}^{-2}$ from the generator, fixed line or gas cylinders. The use of the cylinders has a number of inconveniences associated with a rather high nitrogen consumption - from $28 \mathrm{l} \cdot \mathrm{hr}^{-1}$ in standby mode to $850 \mathrm{l} \cdot \mathrm{hr}^{-1}$ during the active system operation. Noncontact nitrogen heating also cleans the photomultiplier module, prolongs the life of dosimeters and ensures a linear temperature change, which along with high-precision electronic equipment allows obtaining consistent and reproducible luminescence curves in a wide range of readings. Nitrogen continuously feed the system through a reducer providing a constant pressure at the outlet of the generator, fixed line or gas cylinder, in which the gas flow would not exceed $200 \mathrm{l} \cdot \mathrm{min}^{-1}$. If this value and the output pressure are exceeded, the reducer automatically blocks the supply of nitrogen to the reader.

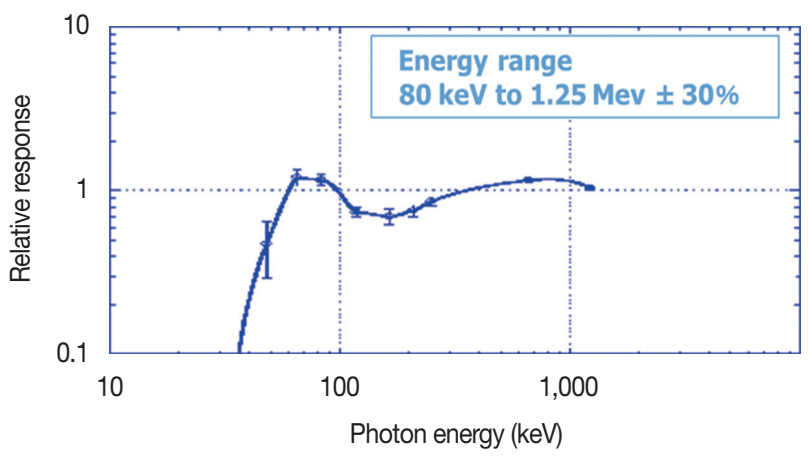

Fig. 5. Energy characteristic of D-Shuttle.
The technical complexity of Harshaw 6600 operation stipulates high measurement performance, reaching 70 and 140 dosimeters per hour for automatic processing of 4 - and 2-chip dosimeters respectively, which is 6 and 12 times higher than that of DVG-02TM. Productivity of DVG-02TM also depends on working capacity of operator, who manually places each crystal detector into the reader.

\section{D-Shuttle, principle and parameters}

The Japanese dosimeters D-Shuttle use a silicon semiconductor crystal detector, although D-Shuttle is designed to record the dose of gamma-radiation and is calibrated by the radioisotope of ${ }^{137} \mathrm{Cs}$. The energy range of radiation of D-Shuttle is limited from $80 \mathrm{keV}$ to $1.25 \mathrm{MeV}$ (Figure 5). The dose limit recorded by D-Shuttle lies in the range from $0.1 \mu \mathrm{Sv}$ to $99.99 \mathrm{mSv}$, and $10 \%$ linearity [5] of measurements is provided when using a dosimeter in the field of gamma-radioactive source, creating a dose rate from $2 \mu \mathrm{Sv} \cdot \mathrm{hr}^{-1}$ to $3 \mathrm{mSv} \cdot \mathrm{hr}^{-1}$.

The convenience of using D-Shuttle dosimeters is that they can accumulate the dose equivalent readings during the year without changing the battery, and to read the results of measurements, it is suggested to use a manual handy indicator or a dedicated workstation with PC-connection. The option of reading out dosimeters by means of handy indicator, which displays both the value of the total dose equivalent accumulated by the detector during the entire period of exposure and the equivalent dose received during the day, allows using D-Shuttle both for the current and the operational IDC. Moreover, the use of dedicated workstation connected to a PC via USB-cable (Figure 6) provides an analog and graphic display of results of measuring the doses received on a specific day and hour of the dosimeter's reference exposure period (Figure 7).

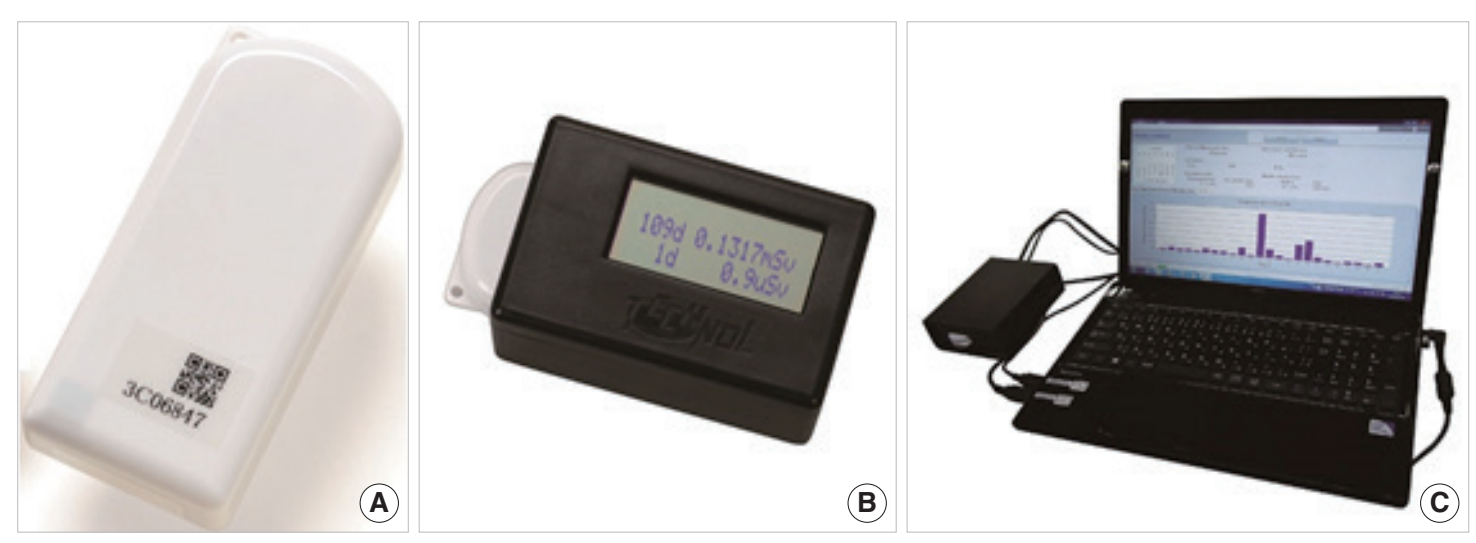

Fig. 6. D-Shuttle dosimeters and their peripheral equipment. (A) D-Shuttle dosimeter, (B) handy indicator, (C) dedicated workstation. 


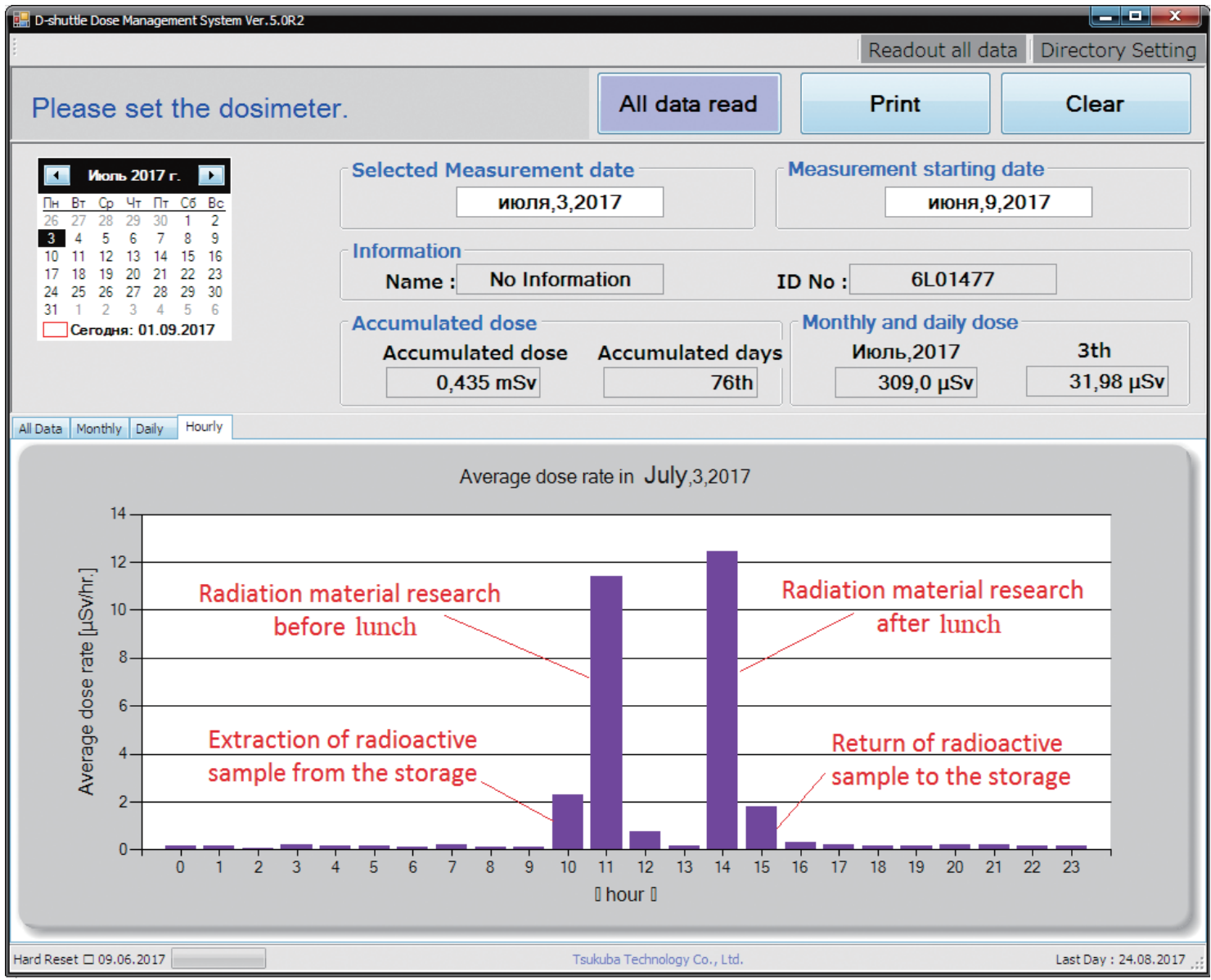

Fig. 7. D-Shuttle dosimeter readings for each hour on July 3, 2017.

However, besides the convenience of using dosimeters and their reading performance, an important technical characteristic of an IDC system is the measurements accuracy.

\section{Radiation metrology facilities and radiation environment}

For intercomparison of Harshaw 6600 and DVG-02TM, different batches of dosimeters of the both types were irradiated with equivalent doses from 0.5 to $20 \mathrm{mSv}$ in the special verification laboratory of the National Center for Expertise and Certification of the Republic of Kazakhstan. Irradiations of Harshaw 6600 and DVG-02TM dosimeters were carried out by means of the verification device of UPGD-2M in the collimated field of cesium ${ }^{137} \mathrm{Cs}$ at temperature of $23-27^{\circ} \mathrm{C}$ and atmospheric pressure of about $766 \mathrm{mmHg}$. For calibration, the primary reference radionuclide source Hopewell Designs IAEA:G10-1-12 with an error of no more than $6 \%$ and an activity of $20 \mathrm{Ci}$ was used.

\section{Experimental Results}

\section{Comparison of the TLDs and D-Shuttle responses on ${ }^{137}$ Cs for $\mathrm{H}_{\mathrm{p}}$ (10)}

Twenty dosimeters of Harshaw 6600 and 25 dosimeters of DVG-02TM had been divided into 5 batches, and each batch was exposed in the collimated field of the reference source of cesium ${ }^{137} \mathrm{Cs}$ at a distance of $50 \mathrm{~cm}$ from it during the automatically determined duration from 6.7 seconds to $4.5 \mathrm{~min}$ utes for irradiating detectors with different doses (0.5-20 mSv). The average results of the comparative measurements carried out after the calibration irradiation of dosimeters are presented in Table 1.

Deviations of Harshaw 6600 and DVG-02TM dosimeters from the corresponding reference doses of calibration exposure are schematically shown in Figure 8, which vividly demonstrates that in both systems the linearity of measurements from 0.5 to $20 \mathrm{mSv}$ does not practically exceed $6 \%$.

To compare the Harshaw 6600 dosimeters with D-Shuttles 
Table 1. Average Results of Readings of Individual Dosimeters of Harshaw 6600 and DVG-02TM Irradiated with Doses from 0.5 to $20 \mathrm{mSv}$

\begin{tabular}{|c|c|c|c|c|}
\hline \multirow{2}{*}{$\begin{array}{l}\text { Reference } \\
\text { radiation } \\
\text { dose } \\
\text { (mSv) }\end{array}$} & \multicolumn{2}{|c|}{ Harshaw 6600 dosimeters } & \multicolumn{2}{|c|}{ DVG-02TM dosimeters } \\
\hline & $\begin{array}{c}\text { Average } \\
\text { indications of } \\
H_{p}(10) \text { (mSv) }\end{array}$ & $\begin{array}{l}\text { Percent } \\
\text { deviations } \\
(\%)\end{array}$ & $\begin{array}{c}\text { Average } \\
\text { indications of } \\
H_{p}(10)(\mathrm{mSv})\end{array}$ & $\begin{array}{c}\text { Percent } \\
\text { deviations } \\
\text { (\%) }\end{array}$ \\
\hline 0.5 & 0.49 & -2.00 & 0.51 & 1.20 \\
\hline 1 & 1.09 & 9.00 & 1.02 & 1.60 \\
\hline 5 & 4.86 & -2.80 & 5.11 & 2.16 \\
\hline 10 & 9.56 & -4.40 & 10.61 & 6.08 \\
\hline 20 & 20.43 & 2.17 & 20.23 & 1.13 \\
\hline
\end{tabular}

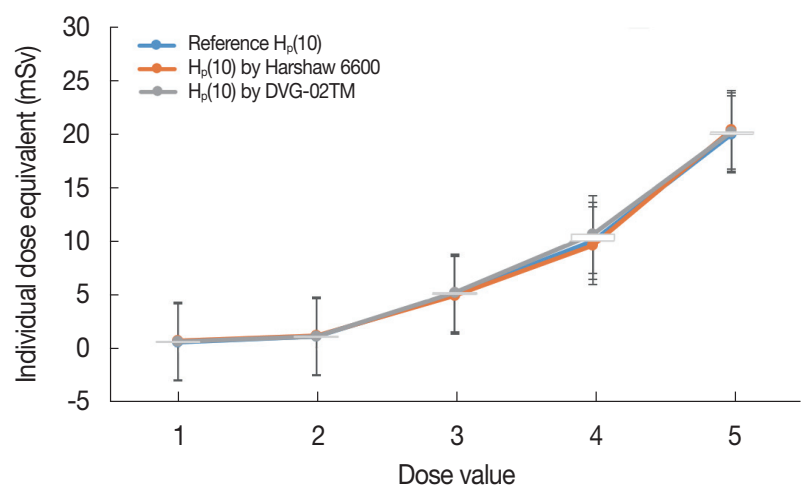

Fig. 8. $H_{0}(10)$ curves of calibration exposure of Harshaw 6600 and DVG-02TM dosimeters.

on measurements accuracy, the individual dosimeters of both types were used in practical operations with ionizing radiation sources in various subdivisions of the Institute of Nuclear Physics of the Ministry of Energy of the Republic of Kazakhstan. Experiments on occupational exposure of TLD Harshaw 6600 and D-Shuttles in gamma- and beta-radiation fields in the absence of weakly penetrating photon radiation with energy of less than $30 \mathrm{keV}$ were performed in compliance with specifications regulating dosimeters' on-body location. On-body position of dosimeter stipulates the standardized value equivalent (Table 2).

Contravention of the order of dosimeters location on the body described in Table 3 can lead to a significant increase in the measurement error, especially when recording $\mathrm{H}_{\mathrm{p}}(0.07)$ and $\mathrm{H}_{\mathrm{p}}(3)$ in fields of weakly penetrating radiation. Thus, when measuring $\mathrm{H}_{\mathrm{p}}(0.07)$ from beta-particles of the ${ }^{60} \mathrm{Co}$ radionuclide, the difference in the results obtained using dosimeters of the same type placed on the arm and on the chest reached three orders of magnitude [6]. Deviation from the requirements for dosimeters location on the body is possible only if one knows the spatial-energy distribution of radiation. For example, the field of beta-radiation can be uniform within
Table 2. Dependence of Individual Dosimeter On-Body Position on the Type of Personal Dose Equivalent Being Determined

\begin{tabular}{|c|c|c|}
\hline Measuring value & $\begin{array}{l}\text { Operation } \\
\text { value }\end{array}$ & $\begin{array}{l}\text { Position of the individual } \\
\text { dosimeter }\end{array}$ \\
\hline $\begin{array}{l}\text { Equivalent dose of the whole } \\
\text { body external irradiation }\end{array}$ & $H_{p}(10)$ & $\begin{array}{l}\text { On the special clothes breast } \\
\text { pocket or inside }\end{array}$ \\
\hline $\begin{array}{l}\text { Equivalent dose of the skin } \\
\text { external irradiation }\end{array}$ & $H_{p}(0,07)$ & $\begin{array}{l}\text { Directly on the surface of the } \\
\text { most irradiated area of the } \\
\text { skin }\end{array}$ \\
\hline $\begin{array}{l}\text { Equivalent dose of the eye } \\
\text { lens external irradiation }\end{array}$ & $H_{p}(3)$ & $\begin{array}{l}\text { On the level of eyes (for example, } \\
\text { on the shackle of glasses) }\end{array}$ \\
\hline $\begin{array}{l}\text { The equivalent dose on the } \\
\text { surface of the lower part of } \\
\text { the woman's abdomen }\end{array}$ & $\mathrm{H}_{\mathrm{p}}(10)$ & $\begin{array}{l}\text { Over the special clothes, in the } \\
\text { lower abdomen area }\end{array}$ \\
\hline
\end{tabular}

Table 3. Average Readings of Harshaw 6600 and D-Shuttle Dosimeters Irradiated from July to September 2017

\begin{tabular}{|c|c|c|c|c|}
\hline No. & $\begin{array}{l}\text { (1) Harshaw TLD } \\
\left(\mathrm{H}_{p}(10), \mathrm{mSv}\right)\end{array}$ & $\begin{array}{l}\text { (2) D-Shuttle } \\
\left(H_{p}(10), m S v\right)\end{array}$ & (1/2) & Field of usage \\
\hline 1. & 0.68 & 0.45 & 1.50 & Research reactor \\
\hline 2. & 0.61 & 0.39 & 1.54 & \\
\hline 3. & 0.47 & 0.25 & 1.88 & \\
\hline 4. & 0.57 & 0.49 & 1.17 & Isochronous cyclotron \\
\hline 5. & 0.61 & 0.54 & 1.13 & \\
\hline 6. & 0.53 & 0.45 & 1.17 & \\
\hline 7. & 0.71 & 0.68 & 1.04 & \\
\hline 8. & 0.54 & 0.48 & 1.12 & \\
\hline 9. & 2.54 & 1.15 & 2.21 & $\begin{array}{l}\text { Laboratory of Radiation } \\
\text { Material Science }\end{array}$ \\
\hline 10. & 0.51 & 0.37 & 1.38 & $\begin{array}{l}\text { Center of radiochemistry } \\
\text { and production of } \\
\text { radioisotopes }\end{array}$ \\
\hline
\end{tabular}

the surface passing along the head and upper body and perpendicular to the incident radiation, when measuring $\mathrm{H}_{\mathrm{p}}(3)$. In this case, it is permissible to a place dosimeter in the breast pocket instead of the cap, but the distances from the head and from the trunk up to the plane of the source must be equal to each other in the operational process.

By means of dosimeters D-Shuttle and Harshaw 6600, $\mathrm{H}_{\mathrm{p}}(10)$ measurements were made in the process of a worker irradiation from the chest (anteroposterior geometry) in the field of uniform (within the body of the irradiated worker) quasi-directional or quasi-isotropic radiation. The dosimeters location on the body is shown in Figure 9.

2. Personnel dosimetry Case 1 comparison of TLDs and D-shuttle for $H_{p}(0.07)$ and $H_{p}(10)$ and $H_{p}(3)$ assuming that both types of TLD badges were closely placed to each other but avoid shadowing of them

To compare D-Shuttle and Harshaw 6600 dosimeters the personnel of the technological service of the WWR-K re- 


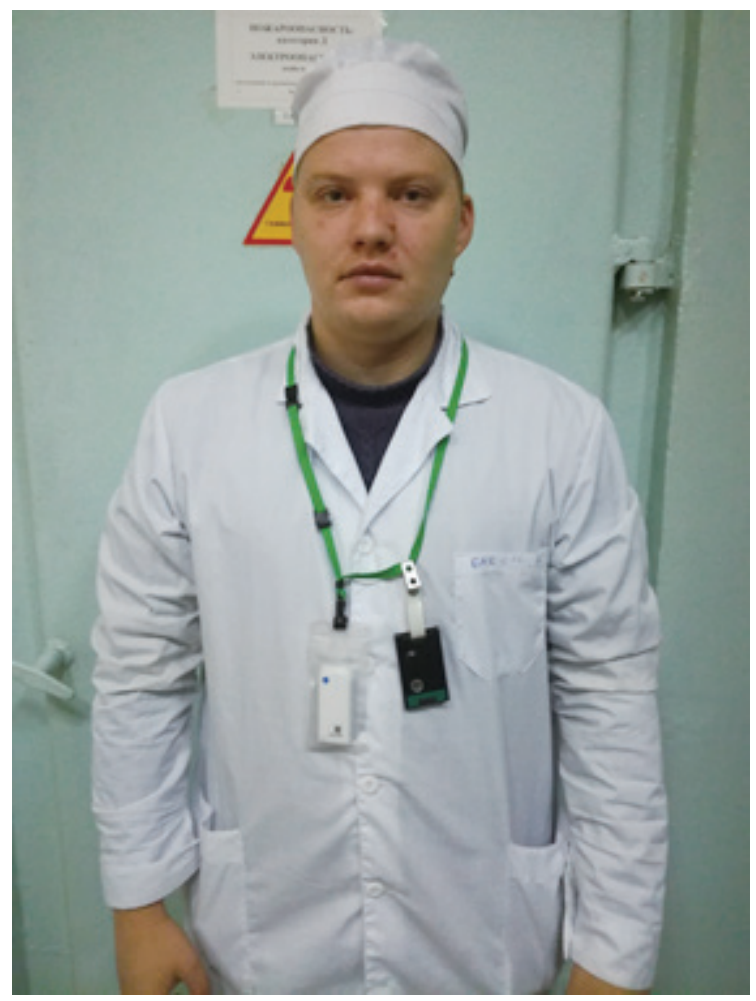

Fig. 9. On-body location of D-Shuttle and Harshaw 6600 dosimeters during exposure.

search reactor, control system engineers of the U-150M isochronous cyclotron, researchers of the Radiation Material Science Laboratory and the Radiochemistry and Radioisotope Production Center used them. The results of dosimeters measurements from July to September 2017 and from October to December 2017 are in Tables 3 and 4 respectively.

\section{Personnel dosimetry Case 2 (in field) including} doses for more than $1 \mathrm{mSv}$ and dose rate more than $3 \mathrm{mSv} \cdot \mathrm{hr}^{-1}$

To compare D-Shuttle and DTL-02 dosimeters the personnel of the radioecological field expedition and branches of the Institute of Nuclear Physics, including Azgir, Aksay and Astana, used them. The results of dosimeters measurements from July to October 2018 are in Table 5.

\section{Discussion}

Differences between indications of Harshaw 6600 and DShuttle dosimeters are schematically shown in Figure 10. The figure clearly demonstrates that when measuring doses are below $1 \mathrm{mSv}$, the results discrepancy does not exceed $35 \%$, but when registering a dose of more than $1 \mathrm{mSv}$ the re-
Table 4. Average Readings of Harshaw 6600 and D-Shuttle Dosimeters Irradiated from October to December 2017

\begin{tabular}{|c|c|c|c|c|}
\hline No. & $\begin{array}{l}\text { (1) Harshaw TLD } \\
\left(H_{p}(10), m S v\right)\end{array}$ & $\begin{array}{l}\text { (2) D-Shuttle } \\
\left(H_{p}(10), m S v\right)\end{array}$ & (1/2) & Field of usage \\
\hline 1. & 0.61 & 0.49 & 1.25 & Research reactor \\
\hline 2. & 0.38 & 0.21 & 1.84 & \\
\hline 3. & 0.31 & 0.17 & 1.87 & \\
\hline 4. & 0.34 & 0.16 & 2.11 & Isochronous cyclotron \\
\hline 5. & 0.24 & 0.13 & 1.78 & \\
\hline 6. & 0.22 & 0.14 & 1.56 & \\
\hline 7. & 0.27 & 0.19 & 1.42 & \\
\hline 8. & 0.22 & 0.16 & 1.37 & \\
\hline 9. & 0.58 & 0.18 & 3.20 & $\begin{array}{l}\text { Laboratory of Radiation } \\
\text { Material Science }\end{array}$ \\
\hline 10. & 0.41 & 0.18 & 2.29 & $\begin{array}{l}\text { Center of radiochemistry } \\
\text { and production of } \\
\text { radioisotopes }\end{array}$ \\
\hline
\end{tabular}

Table 5. Average Readings of DTL-02 and D-Shuttle Dosimeters Irradiated from July to October 2018

\begin{tabular}{ccccc}
\hline No. & $\begin{array}{c}\text { (1) Harshaw TLD } \\
\left(H_{p}(10), m S v\right)\end{array}$ & $\begin{array}{c}\text { (2) D-Shuttle } \\
\left(H_{p}(10), m S v\right)\end{array}$ & (1)/2) & Field of usage \\
\hline 1. & 0.17 & 0.28 & 0.61 & Azgir field expedition \\
2. & 0.16 & 0.27 & 0.60 & \\
3. & 0.20 & 0.28 & 0.70 & \\
4. & 0.15 & 0.27 & 0.57 & \\
5. & 0.18 & 0.28 & 0.63 & \\
6. & 0.15 & 0.22 & 0.65 & Astana branch of INP \\
7. & 0.15 & 0.25 & 0.58 & \\
8. & 0.15 & 0.26 & 0.57 & \\
9. & 0.96 & 1.33 & 0.72 & \\
10. & 0.15 & 0.25 & 0.59 & Aksay branch of INP \\
\hline
\end{tabular}

sults discrepancy is about $50 \%$, and the readings of D-Shuttles are stably lower than of Harshaw 6600 dosimeters. This is because the actual values of the initial exposure levels of Harshaw 6600 TLDs before use are always higher than of the D-Shuttle, although the initial values of the equivalent dose of both dosimeters assume zero. However, the D-Shuttle software calculates the personal dose equivalent as the difference between its final and initial values, whereas the zeroing of the Harshaw 6600 TLD readings before issuing to the personnel cannot completely neutralize the residual background exposure.

The effect of low-energy radiation on measurement results, taking into account the conversion factors given in the ICRP 74 publication [7], is shown in Figure 11.

The ratio of the personal dose equivalents $\mathrm{H}_{\mathrm{p}}(10)$ to $\mathrm{H}_{\mathrm{p}}(0.07)$ obtained with Harshaw 6600 TLDs is from 1.4 to 2.4 in the photon energy range from 20 to $30 \mathrm{keV}$. Thus, low-energy radiation has some effect on the readings of Harshaw 


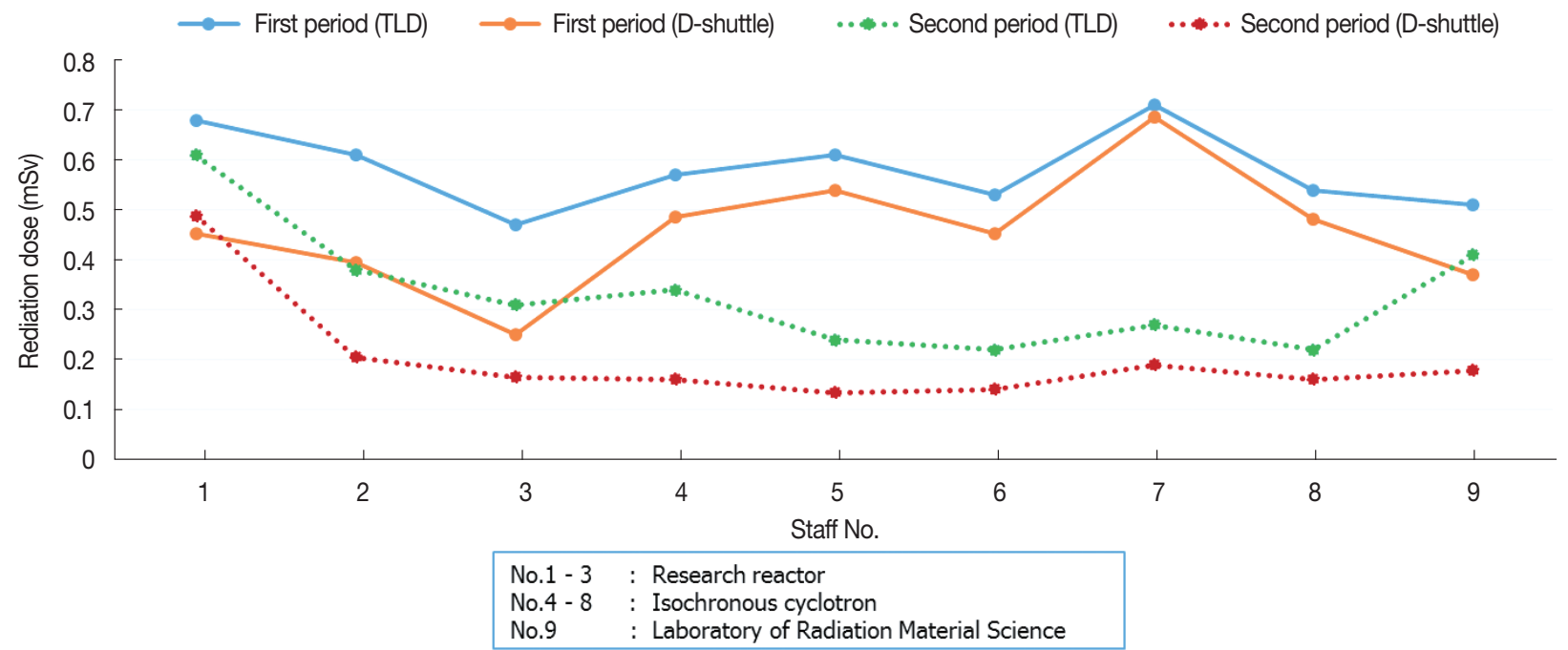

Fig. 10. Comparison of D-Shuttle and Harshaw-6600 exposure results.
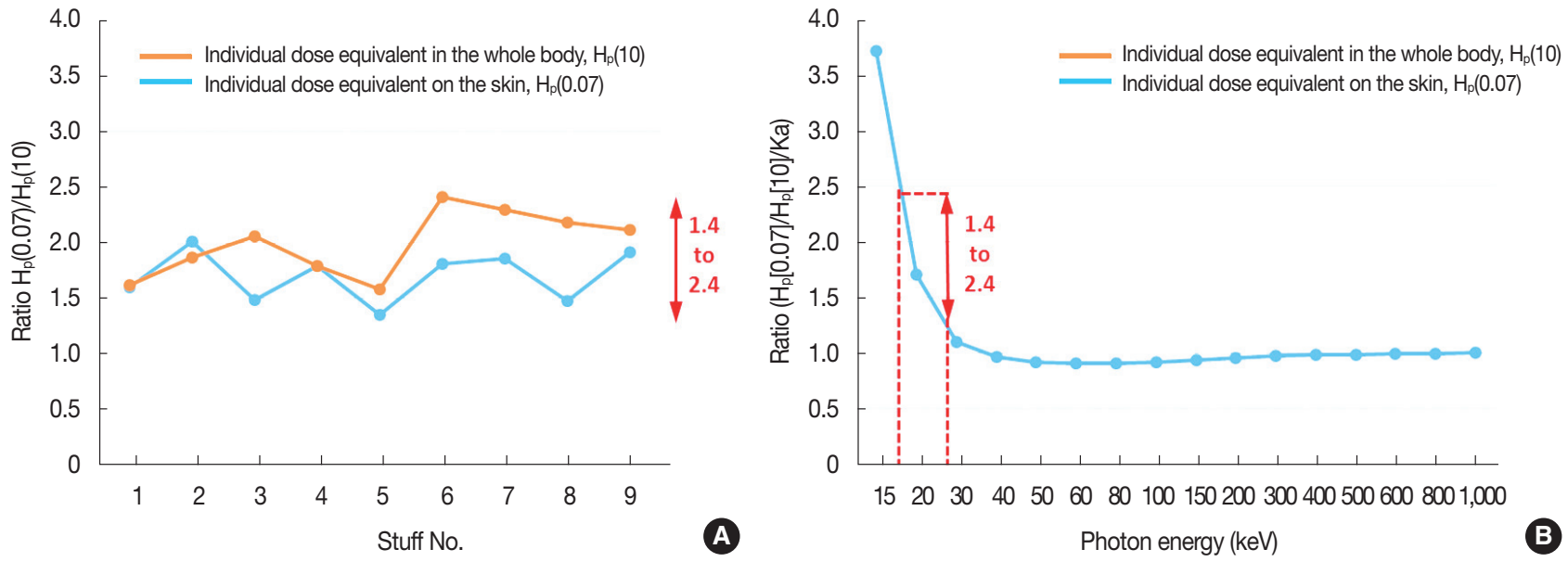

Fig. 11. Influence of low-energy radiation on the results of experimental irradiation of TLD Harshaw 6600. (A) Harshaw 6600 TLDs measurement results, (B) conversion coefficients by ICRP 74.

6600 TLDs, but it is not included in the measurement range of D-Shuttles. Harshaw 6600 does provide the technical ability to measure $\mathrm{H}_{\mathrm{p}}(10)$ and $\mathrm{H}_{\mathrm{p}}(0.07)$ in the same radiation field by means of the same personal dosimeter that contains even two crystal detectors. This is confirmed by the results which were presented in Figure 11A for each staff number who had been equipped with TLDs for Harshaw 6600 and DShuttles as well. When irradiating thermoluminescent dosimeters with high-energy gamma rays like ${ }^{137} \mathrm{Cs}$ or ${ }^{60} \mathrm{Co}$, the entire ionization energy of the phantom is converted to the personal dose equivalent of $\mathrm{H}_{\mathrm{p}}(10)$, so $\mathrm{H}_{\mathrm{p}}(0.07)$ is assumed to be zero. However, accounting for individual dose equivalent on the skin due to Compton scattering was integrated into the computational algorithms of Harshaw 6600, then the re-

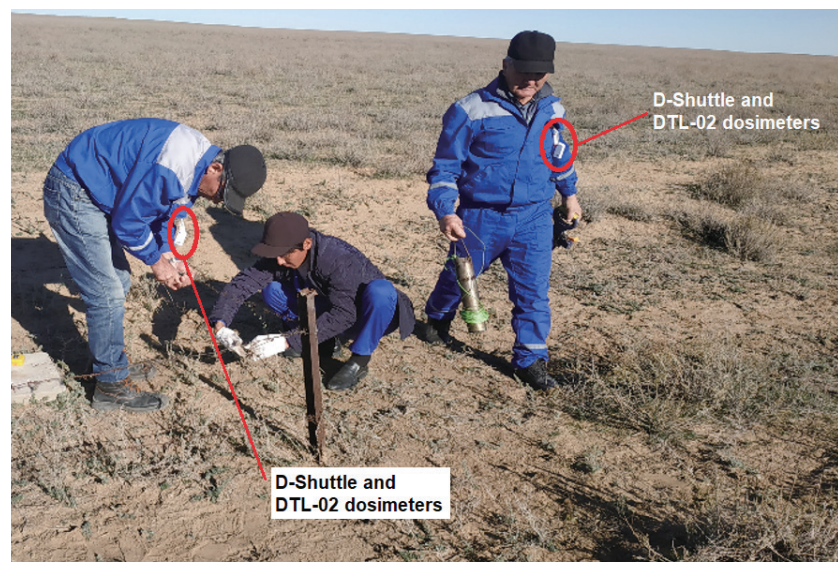

Fig. 12. Location of D-Shuttle and DTL-02 dosimeters on the body during exposure. 
sulting $\mathrm{H}_{\mathrm{p}}(0.07)$ readings from the second crystal detector of a 2-chip dosimeter can be interpreted differently in the Eurasian countries and in the USA.

Table 5 demonstrates that when measuring doses are close to the environmental background of the natural nuclides, the results discrepancy of D-Shuttle and DTL-02 does not exceed $40 \%$. Both D-Shuttle and DTL-02 dosimeters were located on a body as shown in Figure 12. Since dosimeters were located very close to each other, the energy dependence or angular response are unlikely, however indications of D-Shuttle are almost twice higher than of DTL-02. It could be available if only the dose equivalent of the natural irradiation would not exceed $1 \mathrm{mSv}$ per year, when about twofold difference between readout doses in metrological terms is moderate.

\section{Conclusions}

On the base of the results of comparative experiments with dosimeters of Harshaw 6600, DVG-02TM and D-Shuttle, one can draw the following conclusions:

(1) The thermoluminescent systems of the current individual monitoring of ionizing radiation Harshaw 6600 and DVG-02TM are characterized by comparable accuracy of measurements of personal dose equivalents of the external occupational exposure.

(2) At the same time, the obvious advantages of Harshaw 6600 are: high measurement speed, which provides productivity almost an order of magnitude higher than of DVG02TM; the possibility of determining the dose on the skin $\mathrm{H}_{\mathrm{p}}(0.07)$ together with the personal dose equivalent of the whole body irradiation $\mathrm{H}_{\mathrm{p}}(10)$; and durability of thermoluminophores, protected from mechanical damages by the substrate made of teflon or kapton.

(3) Advantages of DVG-02TM consist of the operation simplicity and lower cost in comparison with Harshaw 6600 reader and dosimeters, which have service life of approximately 500 cycles "exposure-measurement".

(4) D-Shuttles provide high level of convenience for reading out the indications and storing the exposure history, which allows them to be used for both the current and the operational individual monitoring of ionizing radiation.

(5) Acceptable accuracy and $10 \%$ linearity of measurements are ensured when D-Shuttle is irradiated with doses of no more than $1 \mathrm{mSv}$ in the field of the source that generates the equivalent dose rate no higher than $3 \mathrm{mSv} \cdot \mathrm{hr}^{-1}$. This allows the use of D-Shuttle in conditions of the uniform irradiation with small doses at a stable level of the technologically changed radiation background.

\section{Acknowledgement}

I would like to thank the former Vice-General Director of the Institute of Nuclear Physics, Pyotr Chakrov, for coordinating the program of this study.

Thanks are due to the Chairman of Chiyoda Technol Co., Toshikazu Hosoda, for helping suggestions and comments in estimating the characteristics of dosimeters.

I wish to express my gratitude to the President of Chiyoda Technol Co., Kazuhiko Yamaguchi, for the support on cooperative study.

I wish to thank Dr. Hiroyuki Ohguchi of Chiyoda Technol Co. for valuable advices.

\section{References}

1. Ministry of National Economy of the Republic of Kazakhstan. Sanitary-epidemiological requirements for ensuring radiation safety. Sanitary rules 261. 2015;12-43.

2. Kudryashev VA, Kim DS, Nurtazin YR, On the standards of individual dosimetry of external radioactive irradiation. Metrological scientific and technical journal "The world of measurements". 2016;174:11-14.

3. Martynyuk AN. DVG-02TM dosimetric thermoluminescent unit; Operating Manual PIGU.412113.003RE. Moscow. JSC SIE Doza. 2005;10-18.

4. Thermo Scientific Harshaw Model 6600 LITE TLD Reader; Operator's Manual \#6600LT-W-O-0810-002. Oakwood Village, Ohio. One Thermo Fisher Way. 2010;250.

5. D-Shuttle Dosimeter Management System (for Research Institutions); Instruction Manual. Oarai. Chyoda Technol Corporation. 2015;27.

6. Cross WG, Böhm J, Charles M, Piesch E, Seltzer SM, Dosimetry of External Beta Rays for Radiation Protection (Report 56). Journal of the International Commission on Radiation Units and Measurements. 1997;29:133.

7. International Commission on Radiological Protection. Conversion Coefficients for use in Radiological Protection against External Radiation. ICRP Publication 74. 1997;18-26. 